\title{
Removal of Heavy Metals from Drinking Water by Magnetic Carbon Nanostructures Prepared from Biomass
}

\author{
Muhammad Muneeb Ur Rahman Khattak, ${ }^{1}$ Muhammad Zahoor, ${ }^{2}$ Bakhtiar Muhammad, \\ Farhat Ali Khan, ${ }^{3}$ Riaz Ullah, ${ }^{4}$ and Naser M. AbdEI-Salam ${ }^{5}$ \\ ${ }^{1}$ Department of Chemistry, Hazara University, Mansehra, Khyber Pakhtunkhwa, Pakistan \\ ${ }^{2}$ Department of Chemistry, University of Malakand, Chakdara, Dir Lower, Khyber Pakhtunkhwa, Pakistan \\ ${ }^{3}$ Department of Pharmacy, Sarhad University of Science and Information Technology, Peshawar, Pakistan \\ ${ }^{4}$ Department of Pharmacognosy, Medicinal, Aromatic, and Poisonous Plants Research Centre, \\ College of Pharmacy, King Saud University, Riyadh, Saudi Arabia \\ ${ }^{5}$ Riyadh Community College, King Saud University, Riyadh 11437, Saudi Arabia
}

Correspondence should be addressed to Muhammad Zahoor; mohammadzahoorus@yahoo.com

Received 7 November 2016; Accepted 21 December 2016; Published 26 January 2017

Academic Editor: Miguel A. Garcia

Copyright ( 2017 Muhammad Muneeb Ur Rahman Khattak et al. This is an open access article distributed under the Creative Commons Attribution License, which permits unrestricted use, distribution, and reproduction in any medium, provided the original work is properly cited.

\begin{abstract}
Heavy metals contamination of drinking water has significant adverse effects on human health due to their toxic nature. In this study a new adsorbent, magnetic graphitic nanostructures were prepared from watermelon waste. The adsorbent was characterized by different instrumental techniques (surface area analyzer, FTIR, XRD, EDX, SEM, and TG/DTA) and was used for the removal of heavy metals ( $\mathrm{As}, \mathrm{Cr}, \mathrm{Cu}, \mathrm{Pb}$, and $\mathrm{Zn}$ ) from water. The adsorption parameters were determined for heavy metals adsorption using Freundlich and Langmuir isotherms. The adsorption kinetics and effect of time, $\mathrm{pH}$, and temperature on heavy metal ions were also determined. The best fits were obtained for Freundlich isotherm. The percent adsorption showed a decline at high pH. Best fit was obtained with second-order kinetics model for the kinetics experiments. The values of $\Delta H^{\circ}$ and $\Delta G^{\circ}$ were negative while that of $\Delta S^{\circ}$ was positive. The prepared adsorbent has high adsorption capacities and can be efficiently used for the removal of heavy metals from water.
\end{abstract}

\section{Introduction}

Presently, the heavy metals contamination in drinking water is being investigated by many scientists in both the natural and anthropogenic sources [1-3]. Heavy metals contaminate both surface and ground water affecting the quality of water as these metals are persistent, toxic, and dangerous to human [4-6]. Around the world the research on finding the more efficient technologies for the water treatment to achieve the safe standards is regularly alarming subject of matter for the environmental scientists.

In past efforts have led to establishing various unit process or operations like adsorption, filtration, precipitation, ion exchange, and chemical coagulation [7-11]. Out of these, the adsorption process is the most economical, technical, and widely used technique [12]. The research on adsorption process for water treatment has resulted in establishing of alternate adsorption materials and methods for the removal of heavy metals from water which includes clay, aluminosilicate, peat, zeolites, kaolin polysaccharides activated carbon, and adsorbents prepared from biomass [12-22].

In this study a novel adsorbent, magnetic carbon nanocomposites were prepared from biomass. The characterization of the prepared adsorbent was carried out by XRD, FTIR, surface area analyzer, Scanning Electron Microscope, EDX, and TG/DTA. This adsorbent was then used for the removal 


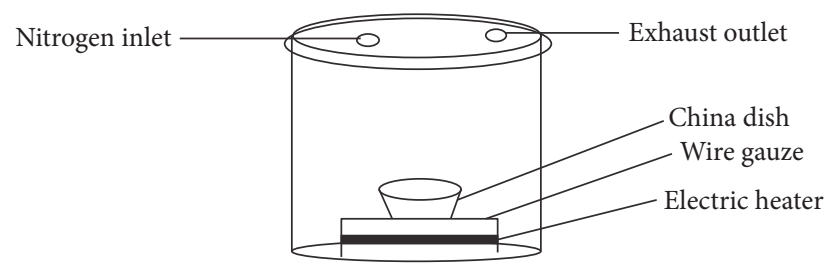

FIGURE 1: The chamber used for preparation of magnetic carbon nanocomposites.

of heavy metals from water as alternative of the conventional adsorbent.

\section{Material and Methods}

2.1. Preparation of Magnetic Carbon Nanocomposites. For the preparation of magnetic carbon nanocomposites the waste of watermelon was collected from local market. The peel of watermelon was dried and cut into pieces and transferred to alcoholic solution of $\mathrm{FeCl}_{3} \cdot 6 \mathrm{H}_{2} \mathrm{O}(10 \% \mathrm{w} / \mathrm{v})$ for $24 \mathrm{hrs}$. The solution and biomass were then separated and dried in open air at room temperature. This dried biomass was then charred and ignited in a specially designed assembly consisting of an electric heater and wire gauze with an inlet for nitrogen and an exhaust outlet for gases (Figure 1).

2.2. Characterization of Iron Oxide Magnetic Carbon Nanocomposites. The most significant physical parameter including the utility and quality of materials is surface area and porosity. Variation in these two parameters greatly influences the activity of the materials. A sample weighing $0.1 \mathrm{~g}$ was taken and characterized by using surface area analyzer of model NOVA 2200e, Quantachrome, made in USA. The purging gas used was nitrogen.

The X-rays diffraction analysis of magnetic nanoadsorbent was carried out by using X-Ray Diffractometer (Joel, JDX-3532) having Ni Filter while monochromatic $\mathrm{Cu} \mathrm{K} \alpha$ was used as a source of radiation which operates at a wavelength of $1.5518 \AA$. The X-ray generator was run at 45 Kilovolt and $30 \mathrm{~mA}$. The speed and range for scanning were $2 \theta / \theta$ and $10 \mathrm{~min}^{-1}$, respectively.

The IR spectra were obtained by analyzing the prepared adsorbent on FTIR (IR Prestige-21, Shimadzu, Japan) whereas the scanning ranges were set for mid-700-500 $\mathrm{cm}^{-1}$ and for Far region 4000-600 $\mathrm{cm}^{-1}$.

Topography of the sample was measured by placing the sample on the grid of SEM, whereas sputter coater was used for gold coating of the sample (made in USA). The image for surface morphology was then recorded by SEM with voltage of $20 \mathrm{KV}$ (Joel JSM-5910).

The prepared adsorbents were analyzed by TG/DTA of diamond series made in USA having a reference of Aluminum trioxide as a standard.

The EDX analysis was performed using EDX model INCA 200.

2.3. Determination of Adsorption Parameters. A series of $25 \mathrm{~mL}$ flasks were taken and concentrations of 150, 175, 200,
TABLE 1: Parameters (physical) of the adsorbent synthesized from watermelon waste.

\begin{tabular}{lc}
\hline BET, surface area $\left(\mathrm{m}^{2} / \mathrm{g}\right)$ & 71.35 \\
Langmuir, surface $\operatorname{area}\left(\mathrm{m}^{2} / \mathrm{g}\right)$ & 261.50 \\
Pore volume total $\left(\mathrm{cm}^{3} / \mathrm{g}\right)$ & 0.63 \\
Micropores volume $\left(\mathrm{cm}^{3} / \mathrm{g}\right)$ & 0.27 \\
Pore diameter, average $(\AA)$ & 115.20 \\
\hline
\end{tabular}

$225,250,275,300,325$, and $350 \mathrm{ppm}$ of standard heavy metals were prepared. A concentration of $0.5 \%(\mathrm{~W} / \mathrm{V})$ of the prepared adsorbent was then added in each flask. These flasks were shaken on orbital shaker at $300 \mathrm{rpm}$ for $480 \mathrm{mins}$ time at room temperature. Every flask was then subjected to magnetic bar for the separation of sorbents. Finally the solution was filtered through Whatman number 1 and then subjected to atomic absorption analysis.

2.4. Determination of Kinetics Parameters. $25 \mathrm{~mL}$ flask series was taken and was spiked with known amount of heavy metal to achieve a concentration of $200 \mathrm{ppm}$. A concentration of $0.5 \%(\mathrm{~W} / \mathrm{V})$ of the prepared adsorbent was then added in each flask and arbitrarily rotated with a speed of 300 revolutions per minute at a temperature of $25^{\circ} \mathrm{C}$. Every flask was then subjected to a magnetic bar for the separation of sorbents. Finally the solution was filtered through Whatman number 1 before atomic absorption analysis.

2.5. Determination of Effect of $\mathrm{pH}$ on Adsorption of Heavy Metals. A series of flasks with $\mathrm{pH}$ ranging from 1 tol4 were prepared to optimize $\mathrm{pH}$ for heavy metals adsorption. Each flask was spiked with standards of heavy metals to achieve 200 ppm before adding the sorbent. Thereafter the sorbents were removed by using magnetic bar after shaking at 300 revolutions per minute for 250 minutes prior to atomic absorption analysis.

2.6. Determination of Thermodynamics Parameters. Another series of flasks was prepared and subjected to similar experimental conditions as mentioned above except for temperatures that were different for each set for a period of 240 minutes. Thereafter, separation and atomic adsorption analysis were carried out.

\section{Results and Discussion}

3.1. Characterization of $\mathrm{Fe}_{2} \mathrm{O}_{3}$ Magnetic Carbon Nanocomposites Made from Watermelon Waste. A special designed chamber as shown in Figure 1 was used to prepare magnetic adsorbent from watermelon waste (peel). The magnetic properties of the prepared adsorbent were noted by subjecting it to the magnetic bar. The attraction of the adsorbent by magnetic bar showed the presence of magnetic oxides in the prepared carbon nanostructures.

Figures 2 and 3 indicated the surface area and pore distribution of magnetic adsorbent, respectively, whereas Table 1 showed different surface parameters of the prepared adsorbent. 


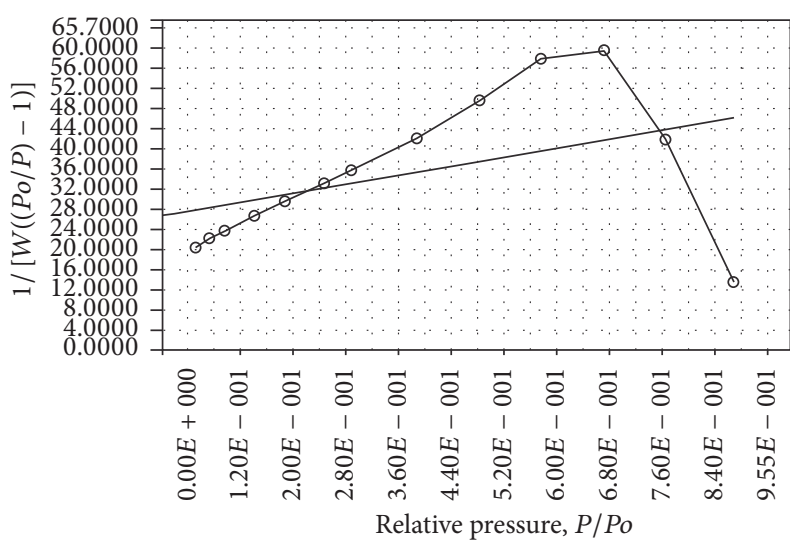

FIGURE 2: Graph showing BET surface area of the prepared iron oxide carbon nanocomposite from watermelon waste.

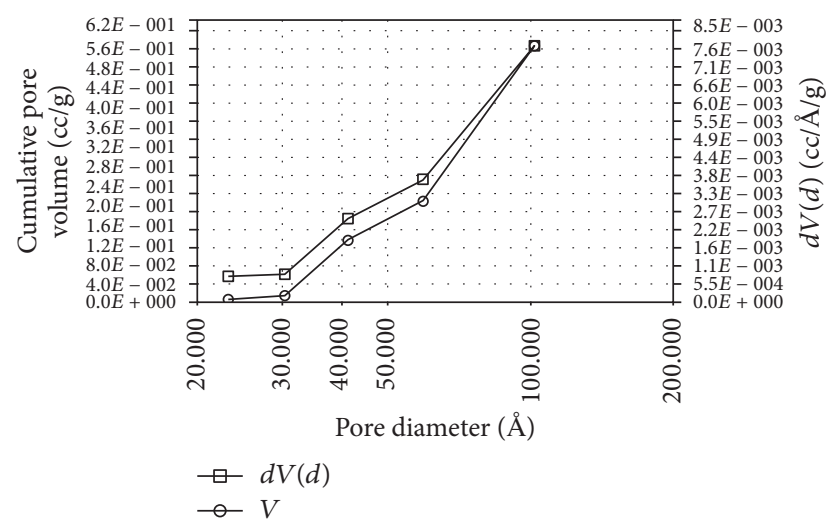

FIGURE 3: Graph showing distribution of pores in the prepared iron oxide magnetic carbon nanocomposites from watermelon waste.

The XRD spectra of the prepared adsorbent from watermelon waste are highlighted in Figure 4, suggesting that $\mathrm{Fe}_{3} \mathrm{O}_{4}$ has been deposited in carbon. XRD not only help in the structure determination but also help in particles size measurement [23]. Peaks of diffraction at $2 \theta$ of $28.35,30.2$, $35.6,40.55,50.2$, and 58.25 indicate corresponding indices $(220,311,400,422,511$, and 440 planes of cubic unite cell) as previously reported for magnetite structure $[24,25]$. The diffraction peaks at $2 \theta$ of $10.45,13.5$, and 20.85 as already reported in literature are related to maghemite and hematite [24]. The size of the prepared adsorbent was calculated by using the equation of Debye-Scherrer.

$$
D=\frac{K \lambda}{\beta \operatorname{Cos} \theta},
$$

where the mean size is represented by $D, K$ is constant (0.94), $\lambda$ is the wavelength (1.55060 $\AA$ ) of X-ray, and $\beta$ shows excess line broadening, while Bragg angle is represented by $\theta$.

$$
\beta=B-b,
$$

where $B$ is the line width (in radian) and $b$ shows instruments line broadening (in radian) [25]. By using formula (1), the

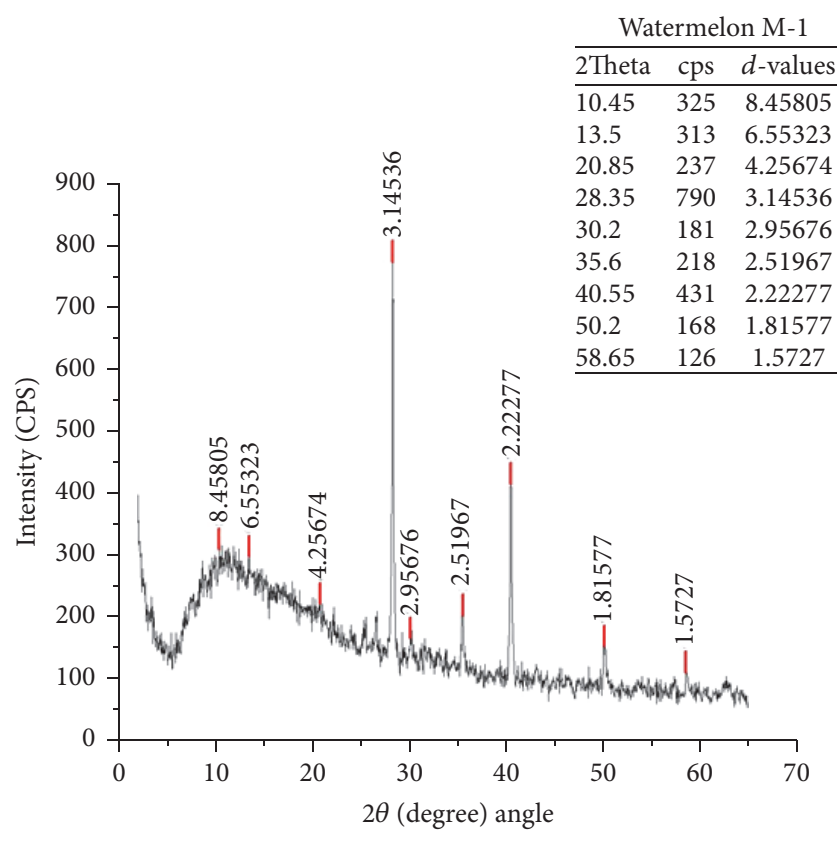

FIGURE 4: XRD spectra of magnetic carbon nanocomposites prepared from watermelon waste.

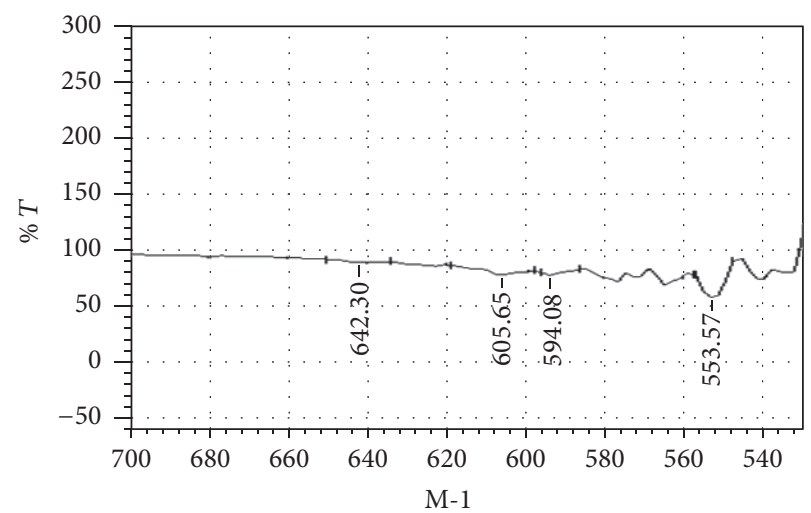

FIGURE 5: Far IR spectra of magnetic carbon nanocomposites prepared from watermelon waste.

sizes of the nanocomposite were calculated and found in the range of $90-250 \mathrm{~nm}$.

For the characterization of the nanocomposite the most widely used technique is the IR Spectroscopy. The IR shows the structure morphology, nature of surface hydroxyl groups, and adsorbed $\mathrm{H}_{2} \mathrm{O}$. At $580 \mathrm{~cm}^{-1}$ and $400 \mathrm{~cm}^{-1}$ broad bands correspond to magnetite structure. The Infrared spectra of iron oxide magnetic carbon nanocomposites prepared from watermelon waste (Far and Mid region) are shown in Figures 5 and 6 . The peaks in range $1000-1200 \mathrm{~cm}^{-1}$ represent C-C and C-O stretching while $573.60 \mathrm{~cm}^{-1}$ of iron oxide represents the deposited magnetite in the prepared adsorbent.

Figure 7 shows the surface morphology of the prepared adsorbent (high and low magnification). The SEM analysis shows the differences in size and shape of the prepared composite. The white patches of the images show crystalline 


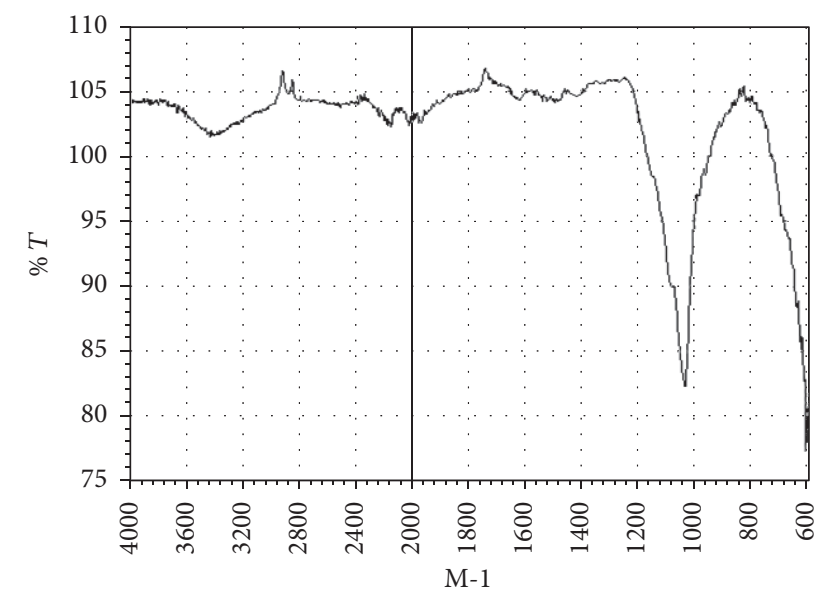

FIGURE 6: Mid IR spectra of magnetic carbon nanocomposites prepared from watermelon waste.

structure of the prepared composite whereas grayish/black spots show the presence of carbon. The aggregation of iron oxide in the photograph is attributed to the contents of moisture absorbed by the prepared adsorbent. The aggregation of particles decreases the surface area of adsorbent and thus decreases its adsorption capacity. It was also observed from the images that the shape of the $\mathrm{Fe}_{3} \mathrm{O}_{4}$ appears somewhat cubical, while the size of nanocomposite was from 50 to $300 \mathrm{~nm}$.

Figure 8 showed the TGA curve for the prepared adsorbent. The spectra show dehydration in two stages. About 9.6\% loss of mass was observed at $400^{\circ} \mathrm{C}$ to $850^{\circ} \mathrm{C}$; however no significant losses were observed above this temperature (up to $970^{\circ} \mathrm{C}$ ). The observed mass loss was due to the dehydration of moisture content from the prepared nanocomposite. In case of DTA analysis two endothermic peaks were seen in the range of $60^{\circ} \mathrm{C}-350^{\circ} \mathrm{C}$.

Figure 9 shows the Electron Dispersive X-ray (EDX) analysis of prepared iron oxide composites of watermelon waste that showed the existence of carbon $(\mathrm{C})$, iron $(\mathrm{Fe})$, and oxygen $(\mathrm{O})$. Also a small peak was observed which represents calcium $(\mathrm{Ca})$ as an impurity. In the prepared iron oxide composites the peaks of $\mathrm{Fe}-\mathrm{K} \alpha, \mathrm{Fe}-\mathrm{L} \alpha, \mathrm{O}-\mathrm{K} \alpha$, and $\mathrm{Fe}-\mathrm{K} \beta$ showed the deposition of iron oxide as also reported by Giles et al. [25].

\subsection{Adsorption Isotherm}

3.2.1. Giles Isotherms. The adsorption of heavy metal on the adsorbents prepared from watermelon waste was studied using Giles isotherm [26]. The Giles adsorption isotherm of the selected heavy metals on iron oxide nanocomposites prepared from watermelon waste is shown in Figure 10. The isotherms for these metals are C type.

3.2.2. Langmuir Isotherm. Langmuir adsorption isotherm assumes that the maximum adsorption corresponds to a saturated monolayer of solute molecules on the adsorbent surface, having no interaction with molecules adsorbed from lateral sides [27]. The linear form of Langmuir isotherm is given as

$$
\frac{C}{q}=\frac{C}{Q_{0}}+\frac{1}{Q_{0} b}
$$

The above equation shows that $q$ represents quantity of adsorbate adsorbed in $\mathrm{mg}^{\mathrm{g}} \mathrm{g}^{-1}, C$ represents the equilibrium concentration of adsorbate in $\mathrm{mg} \cdot \mathrm{L}^{-1}$ while " $\mathrm{Q}_{0}$ " and " $b$ " are Langmuir constants, and " $Q_{0}$ " is the maximum adsorption capacity of the adsorbent and also " $b$ " is the energy of the process.

Langmuir plot of specific adsorption $(C / q)$ against equilibrium concentration $(C)$ for adsorbent prepared from watermelon waste for selected heavy metals is shown in Figure 11. The slope and intercept were used to calculate the values of Langmuir constants $Q_{0}$ and $b$ (Table 2).

3.2.3. Freundlich Isotherm. This isotherm is mostly used to explain the heterogeneous systems [28] and is given by the equation.

$$
\ln q=\ln K+\frac{1}{n} \ln C .
$$

In the above equation $C$ shows the equilibrium concentration in $\mathrm{mg} \mathrm{L}^{-1}, q$ is the amount of adsorbate adsorbed in $\mathrm{mg}$ per gm, and $K$ and $n$ are constants of Freundlich. $K$ shows adsorption capacity while $n$ is the adsorption intensity. The Freundlich constants $K$ and $1 / n$ can be obtained from slope and the intercept of $\ln C$ against $\ln q$ plot.

For the selected heavy metals adsorption on adsorbent prepared from watermelon waste the Freundlich isotherm is given in Figure 12. The values of $K$ and $1 / n$ are given in Table 2.

From Table 2 it is clear that Freundlich adsorption isotherm model fitted the data better than Langmuir isotherm. Also $R^{2}$ values are higher for this model.

\subsection{Adsorption Kinetics}

3.3.1. Effect of Contact Time. In adsorption processes contact time required for reaching equilibrium for an adsorbent is an important factor. For the metals under study the contact time required to reach equilibrium is shown in Figure 13. In first few minutes the uptake of contaminants was very fast as initially more sites of adsorbent are available for adsorption of metals. As the time passes maximum number of sites is occupied by the metals and adsorption process slows down. At the end the equilibrium time of adsorption occurs due to saturation of the adsorbents. The equilibrium time for arsenic, chromium, copper, lead, and zinc was 260, 220, 280, 200 , and 200 minutes, respectively.

3.3.2. Adsorption Kinetic Models. The knowledge regarding adsorption kinetics plays a significant role in the removal of water pollutants. Therefore to evaluate the kinetic parameters, the Lagergren first-order and pseudo-second-order models were used [29]. 


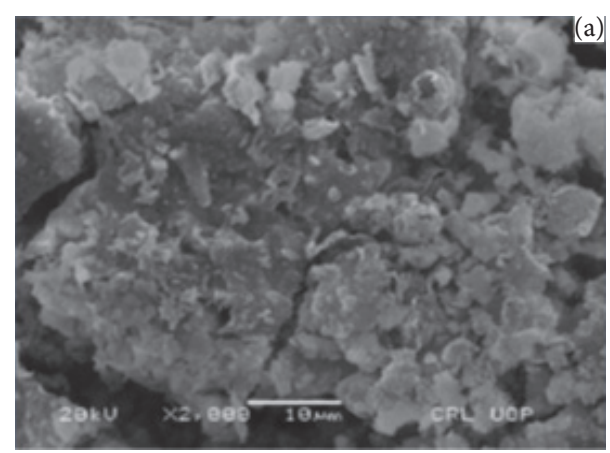

(a)

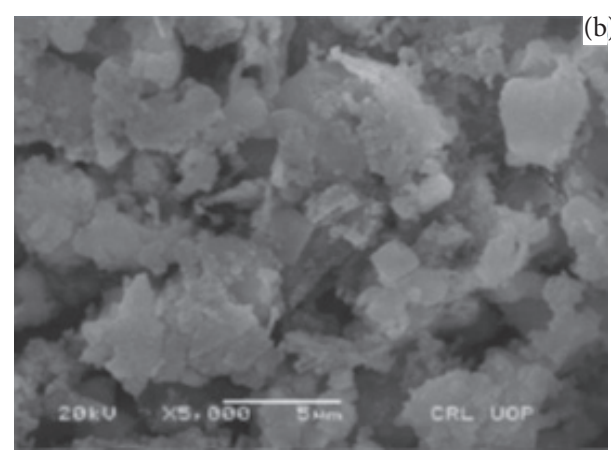

(b)

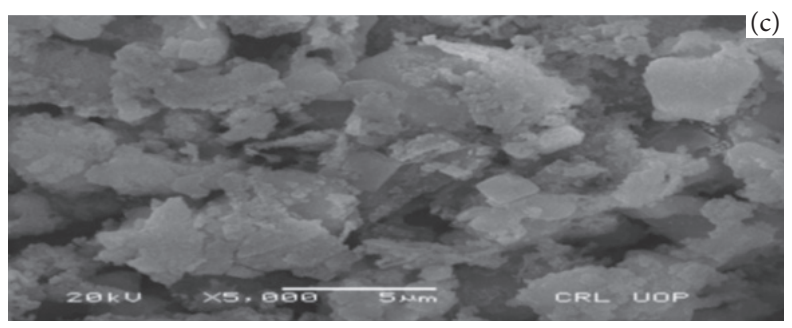

(c)

FIGURE 7: SEM images of magnetic carbon nanocomposites prepared from watermelon waste at different magnification.

TABLE 2: Langmuir adsorption constants for heavy metals on nanostructures from watermelon waste.

\begin{tabular}{|c|c|c|c|c|c|c|}
\hline \multirow{2}{*}{ Heavy metals } & \multicolumn{2}{|c|}{ Langmuir constants } & \multirow{2}{*}{$R^{2}$} & \multicolumn{2}{|c|}{ Freundlich constants } & \multirow{2}{*}{$R^{2}$} \\
\hline & $Q_{0}$ & $b$ & & $1 / n$ & K & \\
\hline Arsenic & 32894 & 0.025 & 0.929237 & 0.9040 & 859.25 & 0.9810 \\
\hline Chromium & 21012 & 0.021 & 0.9274 & 1.0944 & 277.86 & 0.9617 \\
\hline Copper & 38258 & 0.0078 & 0.8194 & 1.004 & 261.25 & 0.9834 \\
\hline Lead & 29837 & 0.0312 & 0.8267 & 0.9156 & 905.87 & 0.9910 \\
\hline Zinc & 18654 & 0.0307 & 0.8192 & 1.1910 & 292.96 & 0.9709 \\
\hline
\end{tabular}

The pseudo-first-order equation can be expressed by the following relation:

$$
\ln (q e-q)=\ln q e-K_{a} t
$$

where $q e$ and $q\left(\mathrm{mg} \mathrm{g}^{-1}\right)$ are the amount of adsorbed adsorbate at equilibrium and time $t$, respectively, and $K_{a}\left(\mathrm{~min}^{-1}\right)$ is the rate constant. $K_{a}$ can be calculated from slope of the plot of $\ln (q e-q)$ versus $t$. This equation shows a linear relationship between $\ln (q e-q)$ and $t$.

$K_{a}$ and $R^{2}$ values (Table 3 ) were calculated by plotting $\ln (q e-q)$ against $t$ for metals under study adsorption on adsorbent prepared from watermelon waste as shown in Figure 14. $K_{a}$ and $R^{2}$ values (Table 3 ) were calculated from $\ln (q e-q)$ versus $t$ plot.

The pseudo-second-order equation can be expressed by the relation

$$
\frac{t}{q_{t}}=\frac{1}{K_{2} q^{2}}+\left(\frac{1}{q}\right) t,
$$

where $K_{2}\left(\mathrm{~g} \mathrm{mg}^{-1} \mathrm{~min}^{-1}\right)$ is the rate constant of adsorption and $q\left(\mathrm{mgg}^{-1}\right)$ is the amount of adsorbate adsorbed at equilibrium and $q_{t}$ is the amount of adsorbate adsorbed at time $t$. The values of $K_{2}$ and $q$ are calculated from intercept and slope of the straight line, respectively.

$K_{a}$ and $R^{2}$ values (Table 3 ) were calculated from plotting $t / q_{t}$ versus $t$ plot (Figure 15 ).

Table 3 shows that the adsorption kinetics could be best explained in terms of the pseudo-second-order rate equation with precision in the correlation coefficients, while the Lagergren rate equation did not reflect the experimental results.

3.3.3. Adsorption Mechanism. In the adsorption process the main steps involved in the removal of adsorbate by adsorbent are the following:

(i) One step is transport of ingoing particles to the external surface of the adsorbent

(ii) Another step is transport of the adsorbate through the pores of adsorbent except for a small amount of the adsorption which occurs on the external surface (interparticle diffusion) and adsorption of the ingoing particles (adsorbate) on to interior surface of the adsorbent 
TABLE 3: Pseudo first- and second-order adsorption kinetics parameters for the adsorption of heavy metals on magnetic carbon nanostructures.

\begin{tabular}{|c|c|c|c|c|}
\hline \multirow{2}{*}{ Heavy metals } & \multicolumn{2}{|c|}{ Pseudo-first-order kinetics model } & \multicolumn{2}{|c|}{ Pseudo-second-order kinetics mode } \\
\hline & $K a$ & $R^{2}$ & $K_{2}$ & $R^{2}$ \\
\hline Arsenic & 0.0158999 & 0.974546 & $2.32 * 10^{-6}$ & 0.992 \\
\hline Chromium & 0.0140065 & 0.994028 & $2.25 * 10^{-6}$ & 0.987 \\
\hline Copper & 0.0124186 & 0.907812 & $6.14 * 10^{-7}$ & 0.968 \\
\hline Lead & 0.0178124 & 0.962160 & $1.72 * 10^{-6}$ & 0.946 \\
\hline Zinc & 0.0162281 & 0.967867 & $2.05 * 10^{-6}$ & 0.989 \\
\hline
\end{tabular}
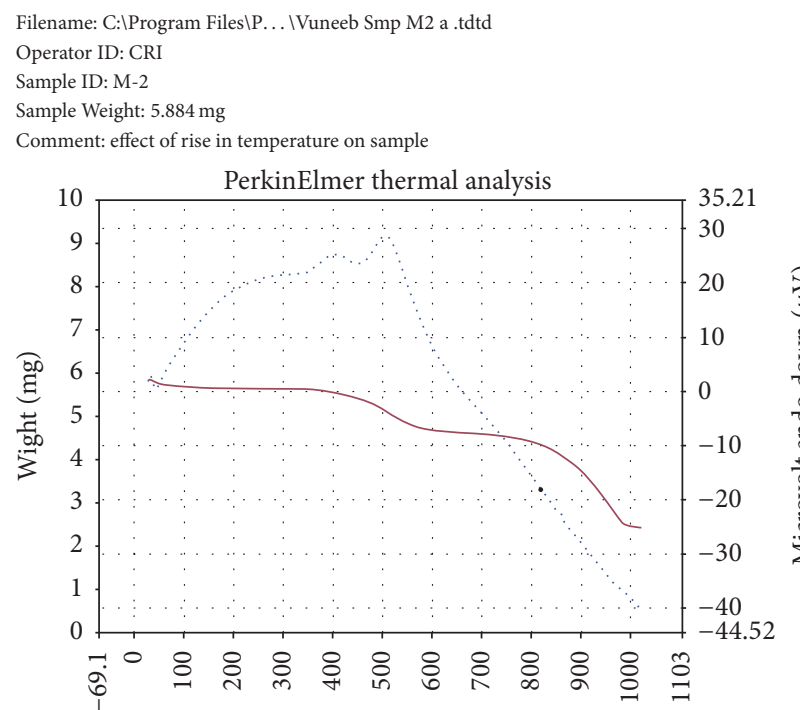

Temperature $\left({ }^{\circ} \mathrm{C}\right)$

(1) Hold for $1.0 \mathrm{~min}$ at $40.00^{\circ} \mathrm{C}$

$$
\begin{array}{ll}
\text { — Wight }(\mathrm{mg}) \\
\ldots \ldots \text { Microvolt endo down }(\mu \mathrm{V})
\end{array}
$$

FIGURE 8: TG/DTA curves of magnetic carbon nanocomposites prepared from watermelon waste.

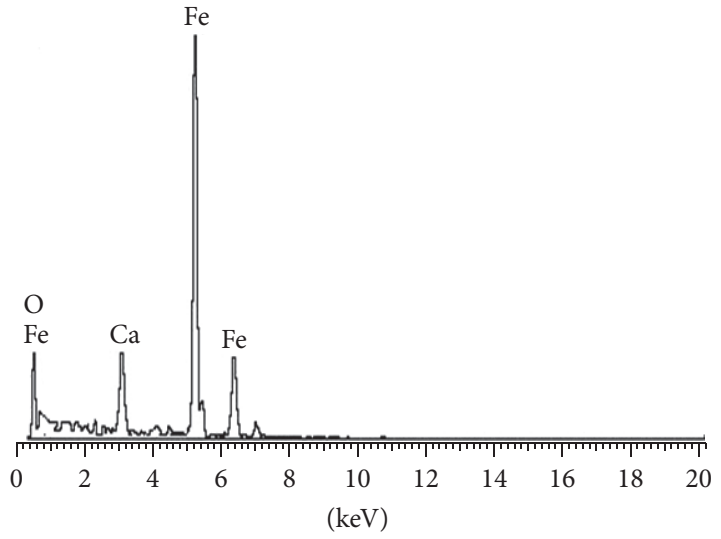

FIGURE 9: EDX spectra of magnetic carbon nanocomposites prepared from watermelon waste.

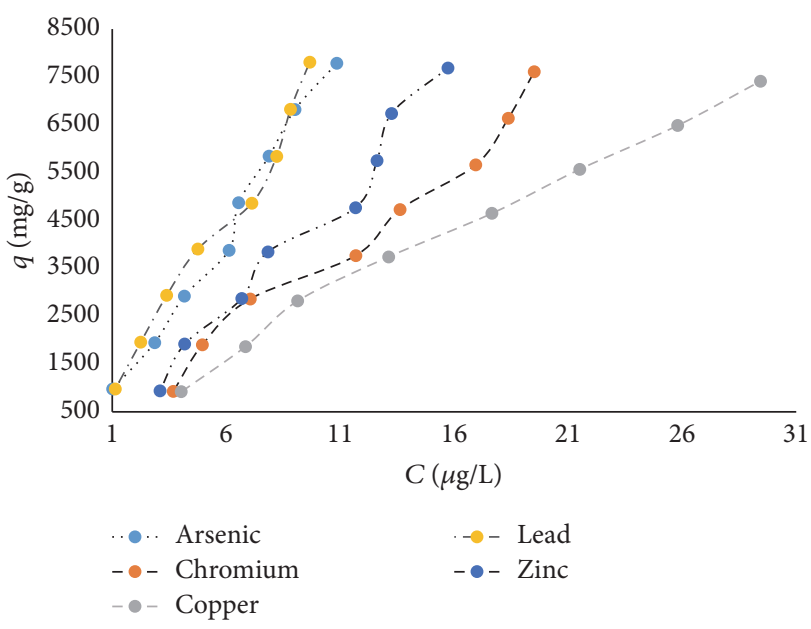

FIGURE 10: Giles adsorption isotherms of heavy metals on adsorbent prepared from watermelon waste.

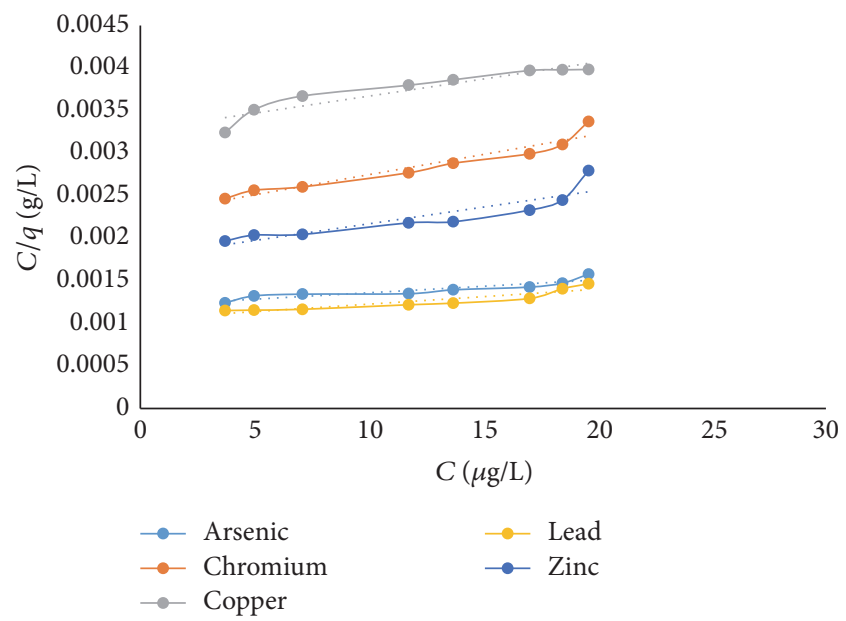

FIGURE 11: Langmuir plot for the adsorption of heavy metals on adsorbent prepared from watermelon waste.

(iii) Amongst these, the rate controlling step, which affects the overall removal rate, is the key step

For the determination of the rate controlling step, intraparticle diffusion model of Weber's is usually used:

$$
q_{t}=k_{i d} t_{1 / 2}+C
$$




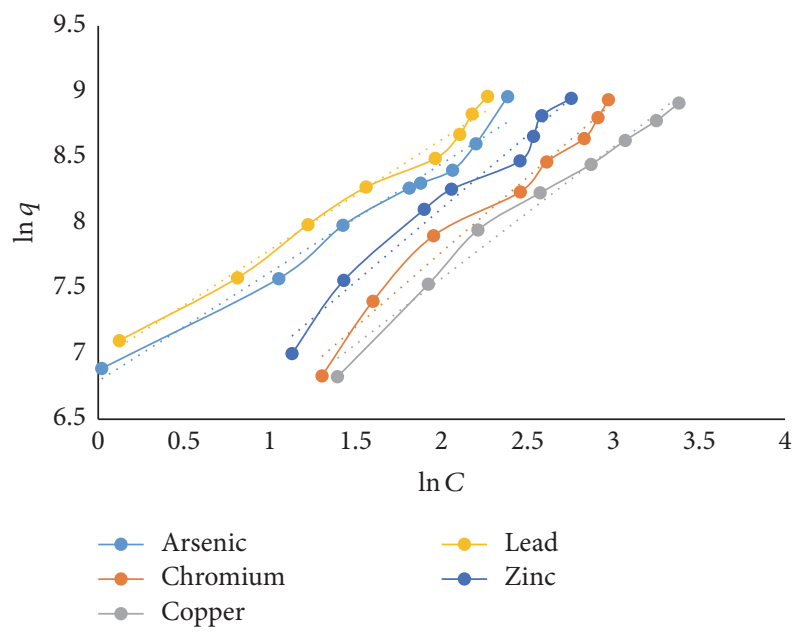

FIGURE 12: Freundlich plot for the adsorption of heavy metals on adsorbent prepared from watermelon waste.

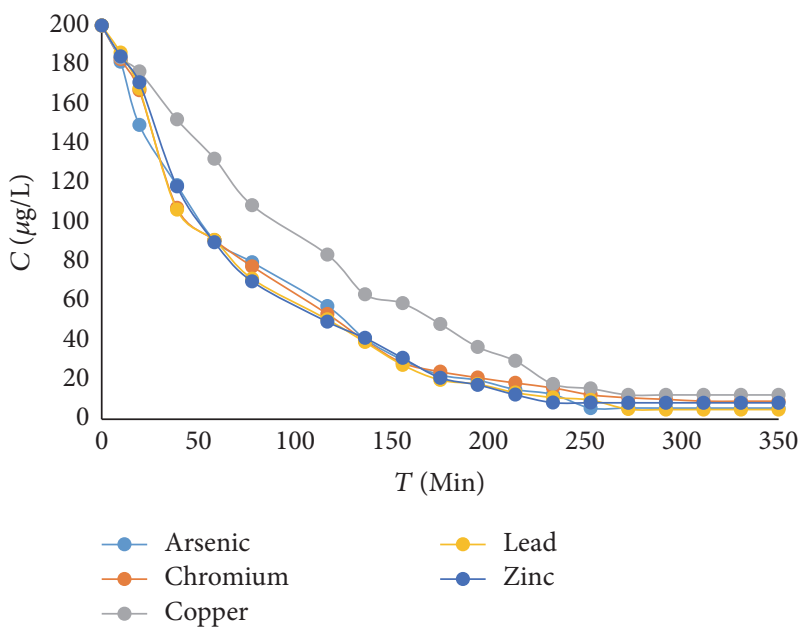

FIGURE 13: Effect of contact time on adsorption of heavy metals on nanocomposites prepared from watermelon waste.

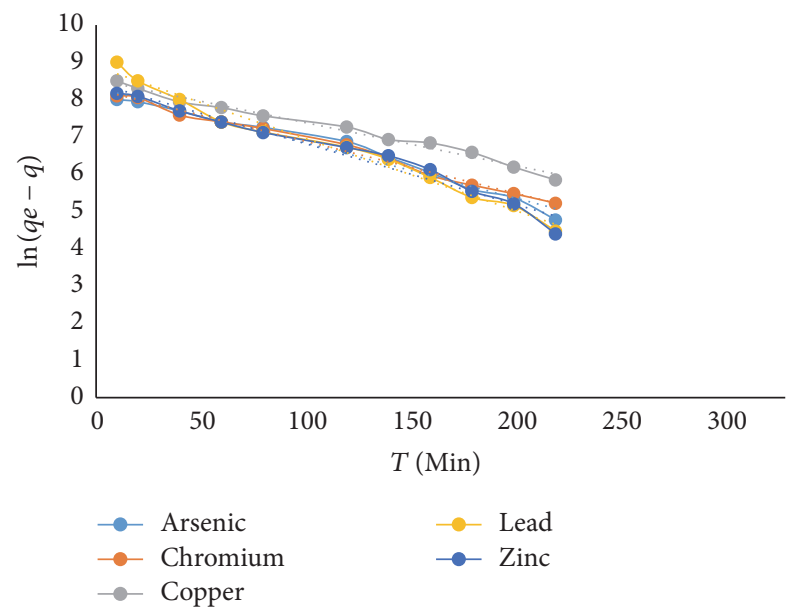

FIGURE 14: Pseudo first-order kinetics plot for the adsorption of heavy metals on nanocomposite prepared from watermelon waste.

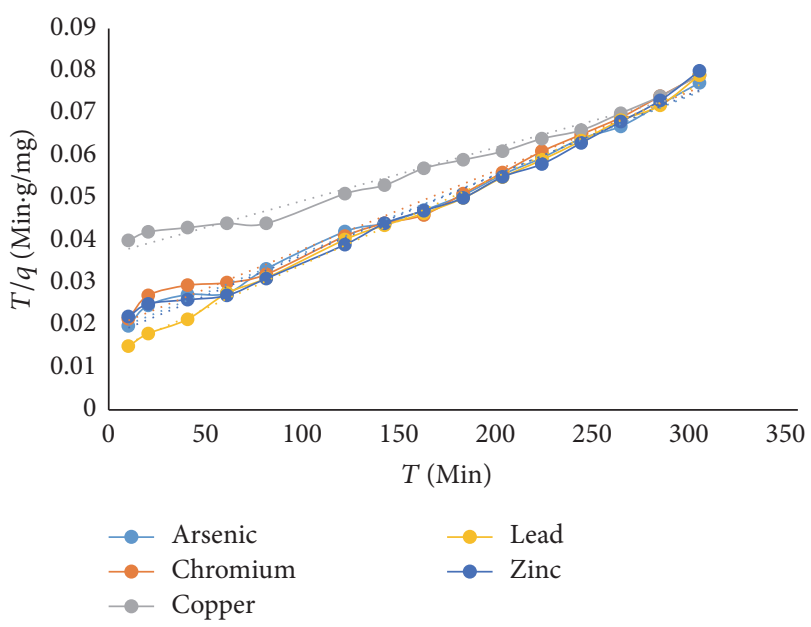

FIgURE 15: Pseudo second-order kinetics plot for the adsorption of heavy metals on nanocomposite prepared from watermelon waste.

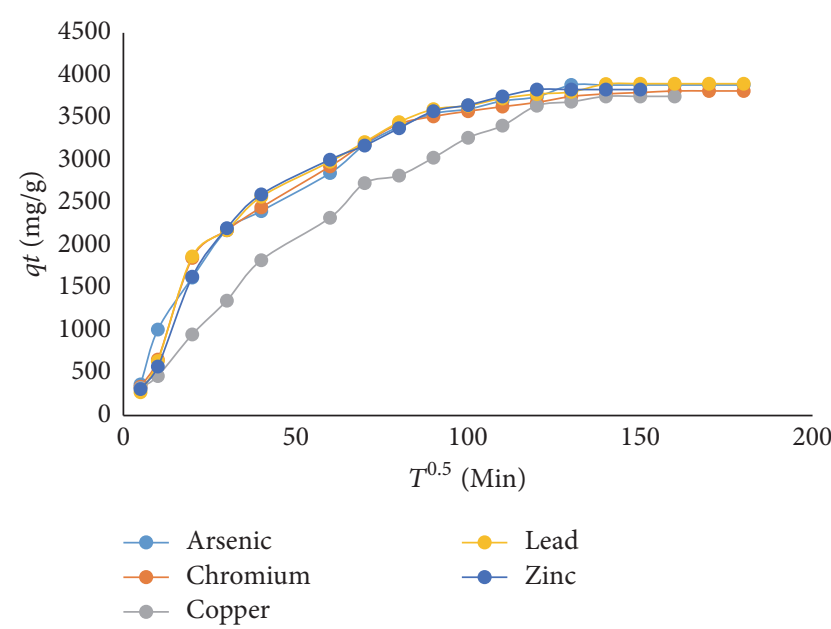

FIGURE 16: Intraparticle diffusion plot for heavy metals adsorption on nanocomposite prepared from watermelon waste.

where $C$ is the intercept and $k_{i d}\left(\mathrm{mg} \mathrm{g}^{-1} \mathrm{~min}^{-0.5}\right)$ is intraparticle diffusion rate constant, which can be evaluated from slope of $q_{t}$ versus $t_{1 / 2}$ plot. If the regression of $q_{t}$ versus $t_{1 / 2}$ is linear and passes through the origin, the only rate-limiting step is intraparticle diffusion.

For the understanding of kinetic mechanism, the amount of heavy metals adsorption on the graphitic magnetic carbon nanostructure prepared from watermelon waste $q_{t}$ was plotted versus the square root of time (Figure 16). Figure showed an initial curve followed by the linear relationship. The initial curve can be explained by the boundary layer effect while the linear part corresponds to the intraparticle diffusion.

The linear plots deviate from the origin clearly indicating that intraparticular diffusion may have more than one controlling steps in selected heavy metals adsorption. 


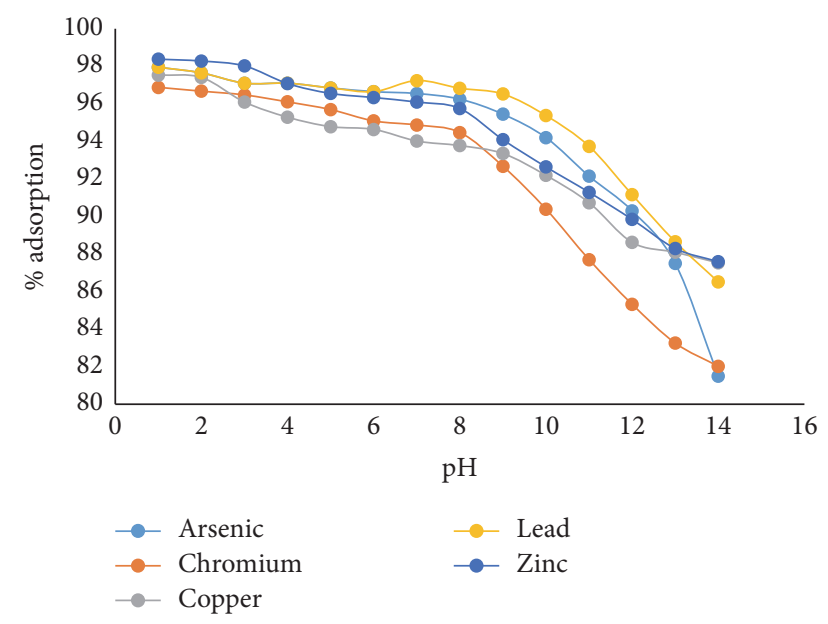

FIGURE 17: Effect of $\mathrm{pH}$ of heavy metals adsorption on magnetic carbon nanocomposites prepared from watermelon waste.

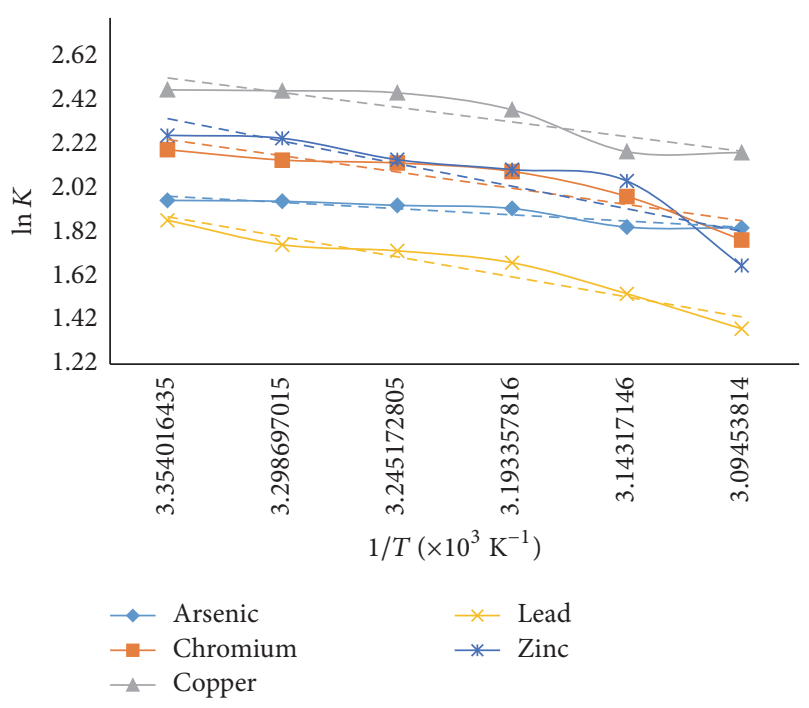

FIGURE 18: Van't Hoff plot for the adsorption of heavy metals on nanocomposite prepared from watermelon waste.

3.4. Effect of $p H$. One of the most important factors that affects the adsorption process is $\mathrm{pH}$ because it affects surface charge of the prepared adsorbent, degree of ionization, and speciation of the adsorbate. The $\mathrm{pH}$ effect on adsorption of selected metals is given in Figure 17. The figure indicated that the adsorption of arsenic at $\mathrm{pH}$ from 1 to 9 was not affected; however a decline was noted at $\mathrm{pH}$ above 9. For chromium from 1 to 7 the adsorption was unaffected; however a decline was noted at $\mathrm{pH}$ above 7. For copper there was a gradual decrease in adsorption with increase in $\mathrm{pH}$. For lead and zinc at $\mathrm{pH}$ from 1 to 10 and 1 to 8 , respectively, there was no effect; however a decline was noted above these ranges.

3.5. Adsorption Thermodynamics. To determine the adsorption thermodynamics, adsorption experiments were carried out at $30,40,50$, and $60^{\circ} \mathrm{C}$. The Van't Hoff equation was utilized to determine $\Delta H^{\circ}$ and $\Delta S^{\circ}$ of the adsorption process.

$$
\ln K=\frac{\Delta S^{\circ}}{R}-\frac{\Delta H}{R T}
$$

$K$ is the distribution constant of adsorption, $\Delta H^{\circ}$ is the enthalpy change, $\Delta S^{\circ}$ is the entropy change, and $T$ is temperature in Kelvin while $R$ is universal gas constant.

The value of $\Delta H^{\circ}$ was calculated from the slope while $\Delta S^{\circ}$ were calculated from intercept of $\ln K$ and $1 / T$ plot (Figure 18) for adsorption of heavy metals on adsorbent prepared from watermelon waste. The values of $\Delta H^{\circ}$ and $\Delta S^{\circ}$ are given in Table 4.

The positive value of $\Delta S^{\circ}$ in Table 4 indicates that, during the adsorption process, there is an increase in the randomness solid/solution system interface whereas the negative values of $\Delta H^{\circ}$ showed that the adsorption on the prepared iron oxide magnetic carbon nanocomposites is an exothermic process.

The values of standard free energy $\Delta G^{\circ}$ were calculated from (9) and are given in Table 4.

$$
\Delta G^{0}=\Delta H^{0}-T \Delta S^{0} .
$$

The spontaneous character of the process is signified by the negative values of $\Delta G^{\circ}$ at different temperatures and shows high affinity of the heavy metals towards the prepared adsorbents. As the values of $\Delta G^{\circ}$ increase with the increase in temperature it is shown that at high temperature the adsorption process is more favorable for the heavy metals adsorption.

Therefore it is concluded that the adsorbent prepared from biomass can be used for the detoxification of heavy metals from water as alternative of powdered activated carbon.

\section{Conclusions}

The removal of heavy metals from water samples was studied by using biosorbent prepared from peel of watermelon and was characterized by surface area analyzer, FTIR, XRD, EDX, SEM, and TG/DTA. Freundlich and Langmuir isotherms were used to determine the adsorption parameters. Other adsorption parameters like adsorption kinetics and effects of time, $\mathrm{pH}$, and temperature were also determined. The best fits were obtained for Freundlich isotherm and with secondorder kinetics model for the kinetics experiments. At high $\mathrm{pH}$ there was a decline in percent adsorption. The values of $\Delta S^{\circ}$ were positive while those of $\Delta H^{\circ}$ and $\Delta G^{\circ}$ were negative. It was concluded from data that adsorbent prepared from watermelon waste has high adsorption capacities and thus can be used as an efficient adsorbent for the removal of heavy metals.

\section{Competing Interests}

The authors have declared no conflict of interests.

\section{Acknowledgments}

The authors are thankful to the Deanship of Scientific Research, King Saud University, Riyadh, Saudi Arabia, for 
TABLE 4: Thermodynamics parameters for the adsorption of heavy metals on carbon nanostructures prepared from watermelon waste.

\begin{tabular}{|c|c|c|c|c|c|c|c|}
\hline \multirow{2}{*}{ Heavy metals } & \multirow{2}{*}{$\Delta H^{\circ}$} & \multirow{2}{*}{$\Delta S^{\circ}$} & \multicolumn{5}{|c|}{$\Delta G^{\circ}$} \\
\hline & & & $25^{\circ} \mathrm{C}$ & $30^{\circ} \mathrm{C}$ & $35^{\circ} \mathrm{C}$ & $40^{\circ} \mathrm{C}$ & $45^{\circ} \mathrm{C}$ \\
\hline Arsenic & -4.0926 & 29.156 & -8.69 & -8.84 & -8.98 & -9.14 & 9.28 \\
\hline Chromium & -9.512 & 55.742 & -16.62 & -16.90 & -17.18 & -17.46 & -17.74 \\
\hline Copper & -10.795 & 54.387 & -16.22 & -16.49 & -16.77 & -17.04 & -17.31 \\
\hline Lead & -14.721 & 61.258 & -18.27 & -18.58 & -18.89 & -19.19 & -19.50 \\
\hline Zinc & -16.645 & 70.944 & -21.16 & -21.52 & -21.87 & -22.23 & -22.58 \\
\hline
\end{tabular}

funding the work through the research group Project no. RGP-210.

\section{References}

[1] A. Demirak, F. Yilmaz, A. Levent Tuna, and N. Ozdemir, "Heavy metals in water, sediment and tissues of Leuciscus cephalus from a stream in southwestern Turkey," Chemosphere, vol. 63, no. 9, pp. 1451-1458, 2006.

[2] P. Chanpiwat, S. Sthiannopkao, and K.-W. Kim, "Metal content variation in wastewater and biosludge from Bangkok's central wastewater treatment plants," Microchemical Journal, vol. 95, no. 2, pp. 326-332, 2010.

[3] S. Muhammad, M. Tahir Shah, and S. Khan, "Arsenic health risk assessment in drinking water and source apportionment using multivariate statistical techniques in Kohistan region, northern Pakistan," Food and Chemical Toxicology, vol. 48, no. 10, pp. 2855-2864, 2010.

[4] A. K. Krishna, M. Satyanarayanan, and P. K. Govil, "Assessment of heavy metal pollution in water using multivariate statistical techniques in an industrial area: a case study from Patancheru, Medak District, Andhra Pradesh, India," Journal of Hazardous Materials, vol. 167, no. 1-3, pp. 366-373, 2009.

[5] S. Venkatramanan, S. Y. Chung, T. H. Kim, M. V. Prasanna, and S. Y. Hamm, "Assessment and distribution of metals contamination in groundwater: A Case Study of Busan City, Korea," Water Quality, Exposure and Health, vol. 7, no. 2, pp. 219-225, 2015.

[6] S. Rapant and K. Krěmová, "Health risk assessment maps for arsenic groundwater content: application of national geochemical databases," Environmental Geochemistry and Health, vol. 29, no. 2, pp. 131-141, 2007.

[7] D. Sud, G. Mahajan, and M. P. Kaur, "Agricultural waste material as potential adsorbent for sequestering heavy metal ions from aqueous solutions-a review," Bioresource Technology, vol. 99, no. 14, pp. 6017-6027, 2008.

[8] A. Demirbas, "Heavy metal adsorption onto agro-based waste materials: a review," Journal of Hazardous Materials, vol. 157, no. 2-3, pp. 220-229, 2008.

[9] D. Mohan and C. U. Pittman Jr., "Arsenic removal from water/wastewater using adsorbents-a critical review," Journal of Hazardous Materials, vol. 142, no. 1-2, pp. 1-53, 2007.

[10] G. Zhang, J. Qu, H. Liu, R. Liu, and R. Wu, "Preparation and evaluation of a novel Fe-Mn binary oxide adsorbent for effective arsenite removal," Water Research, vol. 41, no. 9, pp. 1921-1928, 2007.

[11] P. Mondal, C. B. Majumder, and B. Mohanty, "Laboratory based approaches for arsenic remediation from contaminated water: recent developments," Journal of Hazardous Materials, vol. 137, no. 1, pp. 464-479, 2006.
[12] Y. B. Onundi, A. A. Mamun, M. F. Al Khatib, and Y. M. Ahmed, "Adsorption of copper, nickel and lead ions from synthetic semiconductor industrial wastewater by palm shell activated carbon," International Journal of Environmental Science and Technology, vol. 7, no. 4, pp. 751-758, 2010.

[13] J. Nouri, B. Lorestani, N. Yousefi et al., "Phytoremediation potential of native plants grown in the vicinity of Ahangaran lead-zinc mine (Hamedan, Iran)," Environmental Earth Sciences, vol. 62, no. 3, pp. 639-644, 2011.

[14] G. Issabayeva, M. K. Aroua, and N. M. Sulaiman, "Continuous adsorption of lead ions in a column packed with palm shell activated carbon," Journal of Hazardous Materials, vol. 155, no. 1-2, pp. 109-113, 2008.

[15] Y. B. Onundi and A. A. Mamun, "Adsorption of heavy metals from synthetic industrial wastewater by activated carbon," International Journal of Environmental Science and Technology, vol. 7, pp. 245-261, 2012.

[16] S. P. Singh, L. Q. Ma, and M. J. Hendry, "Characterization of aqueous lead removal by phosphatic clay: equilibrium and kinetic studies," Journal of Hazardous Materials, vol. 136, no. 3, pp. 654-662, 2006.

[17] K. Machowski, P. Natkański, A. Białas, and P. Kuśtrowski, "Influence of thermal treatment conditions on efficiency of PFA/MCM-48 composite and CMK-1 carbon replica in adsorption of volatile organic compounds," Journal of Thermal Analysis and Calorimetry, vol. 126, no. 3, pp. 1313-1322, 2016.

[18] M. Zahoor, "Effect of agitation speed on adsorption of imidacloprid on activated carbon," Journal of the Chemical Society of Pakistan, vol. 33, no. 3, pp. 305-312, 2011.

[19] J. Liu, X. Wu, Y. Hu, C. Dai, Q. Peng, and D. Liang, "Effects of $\mathrm{Cu}$ (II) on the adsorption behaviors of $\mathrm{Cr}$ (III) and $\mathrm{Cr}$ (VI) onto kaolin," Journal of Chemistry, vol. 2016, Article ID 3069754, 11 pages, 2016.

[20] M. Zahoor and F. Ali Khan, "Aflatoxin B1 detoxification by magnetic carbon nanostructures prepared from maize straw," Desalination and Water Treatment, vol. 57, no. 25, pp. 1189311903, 2016.

[21] S. Krehula and S. Musić, "Formation of magnetite in highly alkaline media in the presence of small amounts of ruthenium," Croatica Chemica Acta, vol. 80, no. 3-4, pp. 517-527, 2007.

[22] X.-M. Liu and J.-K. Kim, "Solvothermal synthesis and magnetic properties of magnetite nanoplatelets," Materials Letters, vol. 63, no. 3-4, pp. 428-430, 2009.

[23] M. Sundrarajan and M. Ramalakshmi, "Novel cubic magnetite nanoparticle synthesis using room temperature ionic liquid," $E$ Journal of Chemistry, vol. 9, no. 3, pp. 1070-1076, 2012.

[24] S. A. Kahani, M. Hamadanian, and O. Vandadi, "Deposition of magnetite nanoparticles in activated carbons and preparation 
of magnetic activated carbons. Nanotechnology and its applications," in Proceedings of the 1st Sharjah International Conference, vol. 978, pp. 7354-7439, American Institute of Physics, 2007.

[25] C. H. Giles, T. H. MacEwan, S. N. Nakhwa, and D. Smith, "786. Studies in adsorption. Part XI. A system of classification of solution adsorption isotherms, and its use in diagnosis of adsorption mechanisms and in measurement of specific surface areas of solids," Journal of the Chemical Society (Resumed), pp. 3973-3993, 1960.

[26] I. Langmuir, "The adsorption of gases on plane surfaces of glass, mica and platinum," The Journal of the American Chemical Society, vol. 40, no. 9, pp. 1361-1403, 1918.

[27] H. Freundlich, "Über die adsorption in lösungen (Adsorption in solution)," Zeitschrift für Physikalische Chemie, vol. 57, pp. 384-470, 1906.

[28] S. Lagergren, "Zur theorie der sogenannten adsorption geloester stoffe," Kungliga Svenska Vetenskapsakad. Handlingar, vol. 24, pp. 1-39, 1898.

[29] Y. S. Ho and G. McKay, "Sorption of dye from aqueous solution by peat," Chemical Engineering Journal, vol. 70, no. 2, pp. 115$124,1998$. 

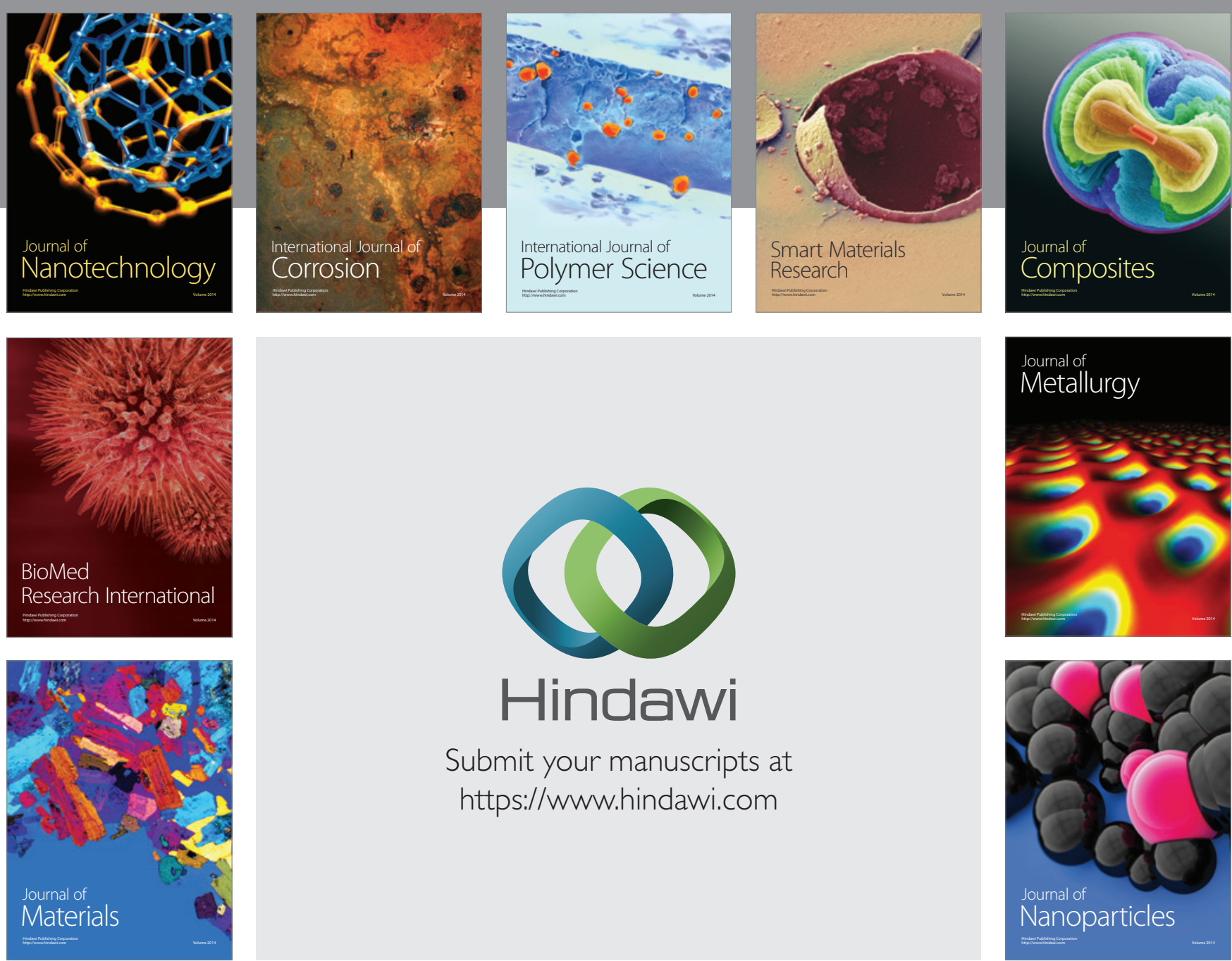

\section{Hindawi}

Submit your manuscripts at

https://www.hindawi.com

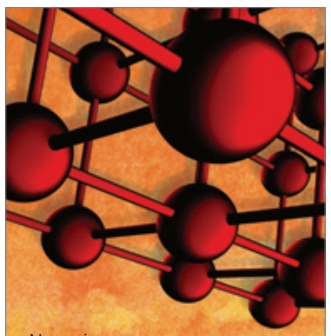

Materials Science and Engineering
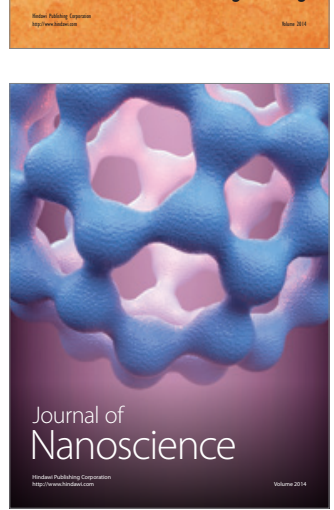
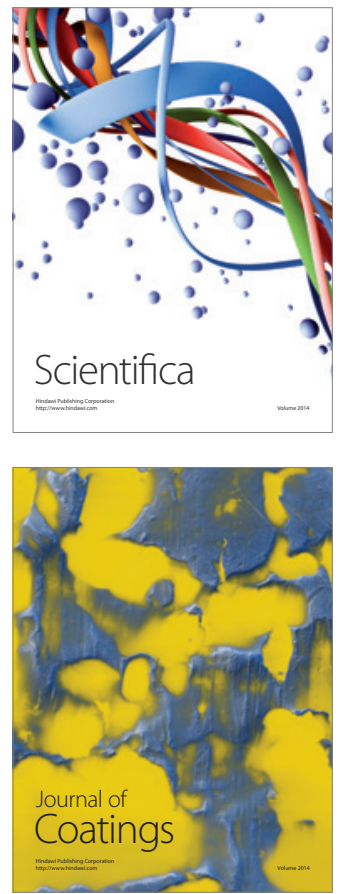
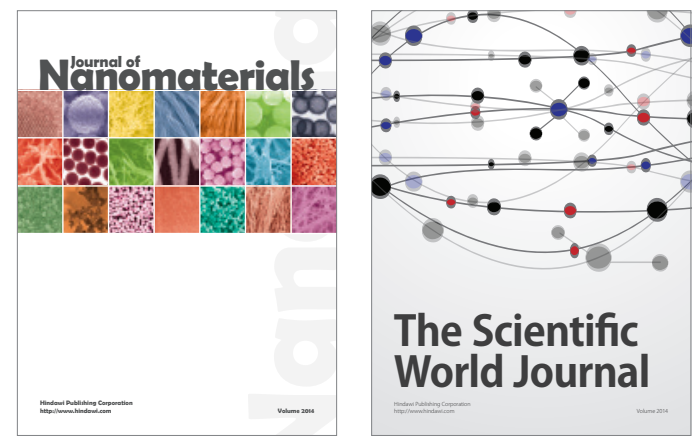

The Scientific World Journal
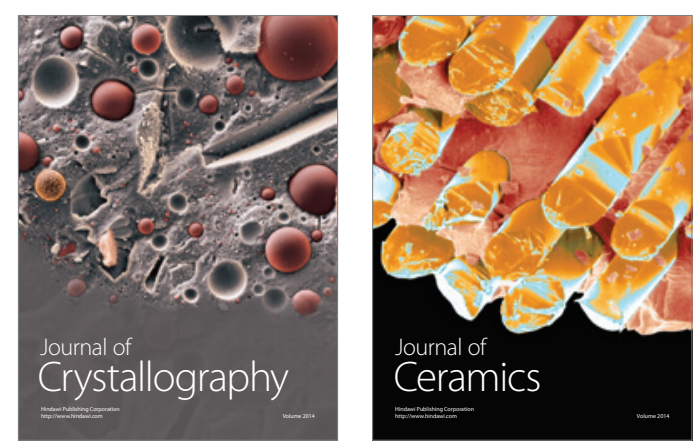
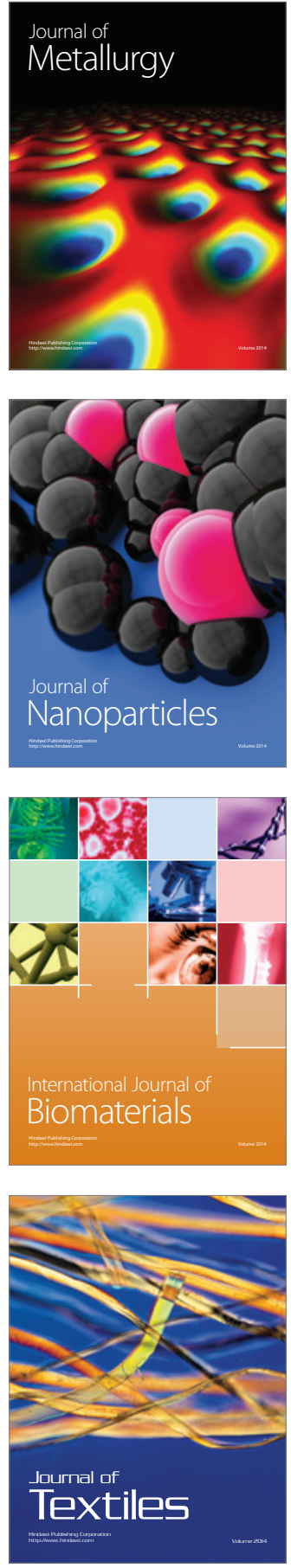